\title{
Measurement of Socioeconomic Position in Research on Cardiovascular Health Disparities in Korea: A Systematic Review
}

\author{
Chi-Young Lee', Yong-Hwan Lee ${ }^{2}$ \\ 'School of Nursing, Duke University, Durham, NC, USA; ${ }^{2}$ Department of Economics, Seoul National University, Seoul, Korea
}

Objectives: The validity of instruments measuring socioeconomic position (SEP) has been a major area of concern in research on cardiovascular health disparities. The purpose of this systematic review is to identify the current status of the methods used to measure SEP in research on cardiovascular health disparities in Korea and to provide directions for future research.

Methods: Relevant articles were obtained through electronic database searches with manual searches of reference lists and no restriction on the date of publication. SEP indicators were categorized into compositional, contextual, composite, and life-course measures.

Results: Forty-eight studies published from 2003 to 2018 satisfied the review criteria. Studies utilizing compositional measures mainly relied on a limited number of SEP parameters. In addition, these measures hardly addressed the time-varying and subjective features of SEP. Finding valid contextual measures at the organizational, community, and societal levels that are appropriate to Korea's context remains a challenge, and these are rarely modeled simultaneously. Studies have rarely focused on composite and life-course measures.

Conclusions: Future studies should develop and utilize valid compositional and contextual measures and appraise social patterns that vary across time, place, and culture using such measures. Studies should also consider multilevel influences, adding a focus on the interactions between different levels of intertwined SEP factors to advance the design of research. More attention should be given to composite and life-course measures.

Key words: Cardiovascular diseases, Health status disparities, Socioeconomic factors, Korea

Received: April 28, 2019 Accepted: August 5, 2019

Corresponding author: Chi-Young Lee, MSN

School of Nursing, Duke University, 307 Trent Drive, Durham, NC

27710, USA

E-mail: c1415@duke.edu

This is an Open Access article distributed under the terms of the Creative Commons Attribution Non-Commercial License (http://creativecommons.org/licenses/bync/4.0// which permits unrestricted non-commercial use, distribution, and reproduction in any medium, provided the original work is properly cited.

\section{INTRODUCTION}

Socioeconomic position (SEP) characterizes the essential aspects of a person's socioeconomic condition and has a distinct impact on promoting or damaging an individual's health [1]. Recent research has shown that significant disparities exist in the health status of populations as multiple functions of SEP [2]. Importantly, analysis of the influence of SEP on cardiovascular health (CVH) outcomes has been a crucial topic, as cardiovascular disease (CVD) has been the dominant cause of death worldwide for at least 50 years [3]. 
Unlike self-reported conditions, which are subject to recall bias and have inconsistent associations with SEP, CVD is arguably the condition for which there is the most evidence of SEP gradients in morbidity and mortality, and for which the major risk factors are large [4]. It has been reported that SEP determines individuals' degree of access to opportunities, including accurate health information, higher-quality health services, and physical and social privileges, while the corresponding disadvantages are closely related to CVH outcomes [5]. Moreover, SEP predicts an adult's ability to cope with unmet medical needs and the financial strain arising from CVD [6]. Underpinning this, CVH disparities due to one's SEP are more direct compared to other diseases with strong genetic components (e.g., sickle cell anemia) and a graded relationship between SEP and CVH outcomes has been documented consistently throughout the literature $[4,6]$.

At the same time, the validity of SEP indicators has been an ongoing challenge in research on CVH disparities [5]. The dynamics of the relationship between socioeconomic condition and CVH depend on the context of SEP [5]. However, SEP may operate in different ways based on the identity, experience, and situation of each individual, making it difficult for a researcher to select an appropriate index [2]. Additionally, the usefulness of SEP is influenced by the validity of either the particular method or the instrument used in its measurement, and inaccurate methods lead to misleading interpretations of study results [7].

In Western societies, researchers have called into question the most appropriate methods for operationalization of SEP measures and discovered areas for improvement to better understand and address CVH disparities [5-9]. In Korea, research has illuminated significant disparities in CVH outcomes in relation to SEP. Nevertheless, little attention has been directed toward examining SEP measures despite their widespread use.

Therefore, the purpose of this systematic review is to identify the gaps in the literature on methodological aspects of SEP in research on CVH disparities in Korea. First, several methods used to measure SEP in research on CVH disparities in Korea are concisely explained, and their shortcomings are then identified in order to provide directions for future research on CVH disparities. Of particular note, in line with the suggestion of Krieger et al. [10], we used SEP, an aggregate concept that includes both resource-and prestige-based measures. The term socioeconomic status was eschewed because it arbitrarily privileges status - over material resources — as the critical determinant of SEP [11]. In addition, this article reports SEP in greater detail, including compositional, contextual, composite, and life-course measures, following the article of Shavers [9].

\section{METHODS}

\section{Study Selection}

A search was performed of PubMed, CINAHL, EMBASE, and Cochrane without a limitation on publication date in order to gain a comprehensive evaluation of the literature (as of June 2018). The search strategy included the key concepts of health disparities, health inequity, socioeconomic factors, socioeconomic environment, and CVH. Specific search terms outlined in Table 1 were used in the literature searches.

\section{Inclusion/Exclusion Criteria}

Only full-text articles published in English or Korean in peerreviewed journals were selected. Further, only studies targeting an adult population (over 19 years old) were included, given that patterns of disparities in children and adolescent may differ from those of adults. Literature drawing upon national comparative studies that included the Korean population was excluded, as choosing the best variable or approach for measuring SEP depends upon its relevance to the population [9]. The searches were extended to include the components of

Table 1. Search terms in PubMed ${ }^{1}$

\begin{tabular}{|c|c|}
\hline Concepts & Search terms \\
\hline Korea & "Korea"[MeSH] or "Republic of Korea"[MeSH] \\
\hline $\begin{array}{l}\text { Cardiovascular } \\
\text { health }\end{array}$ & $\begin{array}{l}\text { "Cardiovascular Diseases"[MeSH] OR death OR mortality OR coronary OR cardiac OR heart OR cardiovascular OR "Myocardial } \\
\text { Ischemia"[MeSH] OR "Myocardial Infarction"[MeSH] OR "Stroke"[MeSH] OR "Cerebrovascular Disorders"[MeSH] OR "Heart Failure"[MeSH] } \\
\text { OR "Metabolic Syndrome"[MeSH] "cardiovascular risk factor" OR "cardiovascular risk factors" OR "Hypertension"[MeSH] OR "Blood } \\
\text { Pressure"[MeSH] OR "Hyperlipidemias"[MeSH] OR "Diabetes Mellitus"[MeSH] OR "Obesity"[MeSH] }\end{array}$ \\
\hline Disparities & $\begin{array}{l}\text { "Socioeconomic Factors"[MeSH] OR socioeconomic OR social OR "Social Class"[MeSH] OR "Health Status Disparities"[MeSH] OR inequalit* } \\
\text { OR disparit* OR inequit* OR "Social Environment"[MeSH] OR "Education"[MeSH] OR "Educational Status"[MeSH] OR "Income"[MeSH] OR } \\
\text { "Poverty"[MeSH] OR "Occupations"[MeSH] OR "Work"[MeSH] OR "Employment"[MeSH] OR "Geography"[MeSH] OR geographic }\end{array}$ \\
\hline
\end{tabular}

${ }^{1}$ The details of non-PubMed searches are available by request. 


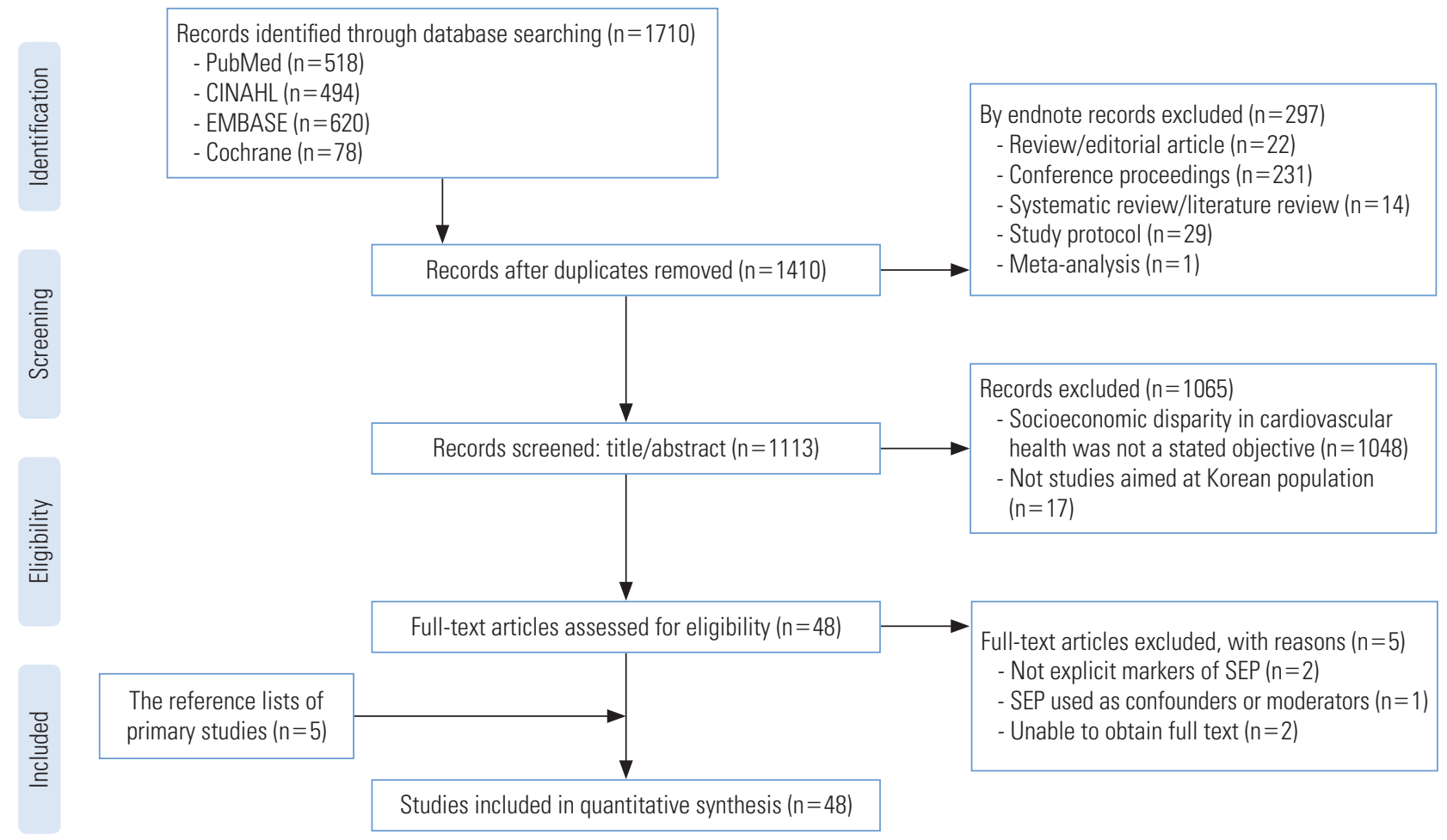

Figure 1. PRISMA (Preferred Reporting Items for Systematic Reviews and Meta-Analyses) flow diagram for search strategy. SEP, socioeconomic position.

cardiovascular risk factors (e.g., diabetes mellitus, hypertension, dyslipidemia, and metabolic syndrome, etc.), specific categories of CVD, and associated mortality as outcome indicators. In this paper, CVD was defined as the summation of coronary artery disease, myocardial infarction, cerebrovascular accident (strokes and transient ischemic attack), peripheral artery disease, and other heart/circulatory diseases.

Publications were omitted for the following reasons: (1) a publication was not a research article or other usable format for a systematic review (e.g., review articles, editorials, conference proceedings, columns, literature reviews, systematic reviews, meta-analyses, and clinical case studies); (2) no definite parameter of SEP was reported (i.e., a homogenous sample of low-SEP or high-SEP groups was observed); (3) SEP was used as a confounder or moderator; or (4) the article was not available.

\section{Data Extraction}

The study selection process, following the PRISMA (Preferred Reporting Items for Systematic Reviews and Meta-Analyses) guidelines, is summarized in Figure 1. A total of 1410 non-duplicate publications were obtained through the initial search.
Each article's title, abstract, and full text were reviewed and assessed for relevance independently by 2 researchers, yielding 43 included articles. Furthermore, the articles were supplemented by manual searches through the reference lists of the retrieved studies. In sum, a total of 48 articles were selected as relevant.

\section{Data Synthesis}

Approaches to SEP were organized into compositional, contextual, composite, and life-course measures, and methodological issues regarding each type of measure were discussed individually (Table 2). Herein, a compositional measure generally represents the individual-level SEP factors that influence the positions an individual holds within the structure of a society. The contextual approach typically focuses on aggregatelevel SEP factors (the social and economic conditions in which one lives that affect individuals) and involves multilevel analyses. Multilevel approaches combine compositional and contextual measures that each measure a different feature of SEP. Composite measures are a combination of 2 or more different SEP factors in a single measure (resulting in a single score) and can be classified into 2 categories: those that measure material 
Table 2. Measurements of socioeconomic position (SEP) in Korean research on cardiovascular health disparities

\begin{tabular}{lll} 
Category [Ref] & \multicolumn{1}{c}{ Main examples } & Limitations \\
\hline $\begin{array}{l}\text { Compositional } \\
\text { SEP measures }\end{array}$ & $\begin{array}{c}\text { Education, income, occupation, health } \\
\text { insurance }\end{array}$ & $\begin{array}{c}\text { Reliant on limited aspects of SEP, while depend- } \\
\text { ing on a few parameters }\end{array}$ \\
& & \\
& & \\
& Hardly address time-varying features of SEP due & to mostly being assessed cross-sectionally \\
Largely focus on objective SEP measures
\end{tabular}

Contextual SEP measures

Organizational Exposure to hazardous conditions, health level [46-49] resources in the workplace, workplace culture, physical exertion, welfare facilities

Community Demographic, socioeconomic, behavioral, level [50-55] and health characteristics of the community according to county- or borough-level administrative boundaries

Societal level One's welfare status

$[25,50,56]$

Multilevel analyses $[46,48.50,55]$

Combining compositional measures with either organizational-level or community-level measures

Composite SEP Material and social deprivation

measures (Carstairs Index)

$[50,52,55]$

Life-course SEP measures $[54,57-59]$
Only employ measures that describe the physical aspects of the working environment, without considering social or psychological aspects

Crude proxies for the places in which people live their lives

Lack a wide range of upstream factors that affect a society's health status

Rarely consider different SEP levels in the model

Limited statistical methods are used for analyzing area data

Reliant on an index more frequently used in Western cultures
Using SEP measures when their concepts can only be captured in the sensitive period model or social mobility model in the life-course
Suggestions

Use cluster analysis for socioeconomic classification

Employ a composite measure based on social standing or prestige

Capture the dynamic and changing features of SEP

More attention on subjective SEP measures that reflect an individual's perception of socioeconomic standing

Adopt a comprehensive set of work-related factors

More rigorous analysis of geographical differences in health (neighborhoods, townships, and towns)

Explore various upstream contextual forces that influence the population health appropriate to a country's circumstances

Focus on interactions between different levels of intertwined SEP factors to advance research design

Use an originally developed and established area-deprivation index for the Korean context

Develop and test an index that can specifically predict cardiovascular health outcomes approach

Viewing them as competing measures that Adopt more comprehensive life-course SEP measures related to 4 life-course models Consider SEP measures related to 4 models within the same analytic model and social deprivation and those that measure social standing or prestige. Finally, life-course measures represent SEP over different time points across a life trajectory.

\section{Ethics Statement}

This paper is a systematic review so it did not need ethical consideration.

\section{RESULTS}

\section{Compositional Socioeconomic Position Measures}

Thirty-four studies (71.0\%) employed a compositional approach to measuring SEP. Of those 34 studies, 17 depended on a single parameter and classified SES level according to a continuous or dichotomous distribution or standardized categori- zation. In these studies, the principal indicators were traditional measures of education [12-18], household income [19-21], and occupation $[22,23]$. Some studies specified the SES level according to proxy measures such as type of health insurance or health-insurance premium levels, which are determined in proportion to one's comprehensive living status [24-28].

Twelve studies were based on 2 or 3 of the above indicators [29-37]. In particular, 3 studies [38-40] used a combination of traditional measures; they stratified SEP into 3 groups using level of education and income and evaluated their association with metabolic syndrome and coronary heart disease risk (the higher SEP corresponded to highest education and household income, the lower SEP correspond to lowest education and household income, and the remainder were framed as middle class). Three studies [41-43] employed a wide array of SEP fac- 
tors as predictors, each of which was investigated separately for its effect on $\mathrm{CVH}$ outcomes. There was a single exception that did not conform to any of the described methods: Chung et al. [44] calculated the interaction values of various individual SEP indicators on a multiplicative scale and determined their roles in obesity risk.

Although SEP was measured cross-sectionally rather than longitudinally in most studies, 1 study included the person's changing occupational status (employed/voluntary retirement/ involuntary job loss) among the prognostic predictors, encompassing the time-dependent aspects of SEP [45]. Further, another study included self-rated living standard as a subjective SEP measure [43], while stratification of SEP mainly relied on mathematical calculations or certain standard classifications.

\section{Contextual Socioeconomic Position Measures Organizational level}

Four studies (8.0\%) used organizational-level SEP measures, which represent relations with the organizational environment, such as workplace settings, that may influence health conditions. In particular, they explored the association between physical work environment and CVH outcomes. Hwang and Park [46] explored the occupational environment (the ratio of healthcare providers to the number of workers, the presence of a cafeteria in the workplace, and the presence of a resting area in the workplace), exposure to hazardous conditions (chemical hazard exposure, noise exposure), and the presence of healthcare monitoring managed by an occupational health nurse; Kim et al. [47], Yoon et al. [48], and Jang et al. [49] included regular working time, duration of strenuous activity during regular work, and shift work as measures of SEP.

\section{Community level}

Six studies (12.5\%) explored within-country variations in morbidity and mortality of CVD with associated community characteristics at the district level to explain geographical disparities [50-55]. The variables that represented different factors influencing disparities included demographic, socioeconomic, health, and behavioral characteristics of the community. In these studies, the gun and gu units, which correspond to county-level or borough-level administrative regions, respectively, were used as geographical units to provide coverage across smaller areas in Korea.

\section{Societal level}

Three papers (6.0\%) discussed these issues from a public health perspective, placing responsibility for achieving health equity at the societal level and emphasizing welfare status as a factor that reduces differences in CVH outcomes across patients $[25,50,56]$. In particular, studies divided the population into those covered by National Health Insurance (NHI; i.e., the employed and self-employed insured, along with their dependents) and Medical Aid; the former category was first arranged, then subdivided into quintiles based on income level, while the latter was classified separately and ranked as the bottom group. For instance, Kim et al. [56] examined the socioeconomic disparities in hospital mortality between NHI patients and Medical Aid patients according to both access to and quality of health services, determined by inpatient quality indicators.

\section{Multilevel analyses}

Four studies (8.0\%) conducted multi-level model analyses, taking into account the hierarchical structure of the data to estimate the effect of related factors at different levels. One study by Hwang and Park [46] investigated individual and organizational levels of CVD risk factors associated with CVD risk in Korean blue-collar workers. Individual factors included type of occupation and socio-demographic factors, and organizational factors included a hazardous environment and job strain, all of which have a potentially negative influence on CVH. Similarly, Yoon et al. [48] explored the influence of the combination of type of work and working hours on the prevalence of obesity among the female working population. In addition, Cho et al. [50] and Shin et al. [55] explored the combined impact of individual household income and neighborhood deprivation level on all-cause mortality in patients with newly diagnosed hypertension and dyslipidemia.

\section{Composite measures}

Three studies (6.0\%) adopted a composite SEP measure that measured material and social deprivation. For instance, previous studies examined the effect of neighborhood-level deprivation on all-cause mortality in patients with newly diagnosed hypertension [50], dyslipidemia [55], and outcomes from outof-hospital cardiac arrest [52]. In these studies, area deprivation indices based on the Carstairs Index were calculated for each of the districts across the country. This index is based on four variables: residents in households headed by unskilled 
workers, unemployed males, residents in overcrowded households, and residents without a car.

\section{Life-course measures}

Four studies (8.0\%) adopted life-course SEP measures. Two studies adopted adult height as a proxy for early-life SEP factors and explored its relationship with morbidity or mortality from cerebrovascular disease [54,57]. Choi et al. [58] adopted parental education level and job status during childhood as early-life factors that predispose individuals to metabolic syndrome in later life. Ko and Kim [59] examined changes in SEP from early life to adulthood (stable high, improving, declining, and stable low) and how they influenced later blood pressure results.

\section{DISCUSSION}

This systematic review yielded 48 studies on the topic of CVH disparities, and approaches to SEP were organized into compositional, contextual, composite, and life-course SEP measures. Most studies adopted a compositional approach to measuring SEP. However, these methods pose limitations for properly quantifying SEP.

First, most studies evaluated limited aspects of SEP, depending on a small number of parameters. Growing evidence suggests that multiple factors of SEP are interrelated and cannot affect health in an independent manner $[11,60]$. Importantly, Khang and Kim [43] highlighted the need to gauge the complexity of SEP by employing a wide range of indicators to illuminate the risk of disparity in socioeconomically vulnerable groups in Korean society. As an analytic solution, cluster analysis for socioeconomic classification or a composite measure of social class provides a meaningful interpretation of the multidimensional concept of SEP by including various SEP factors that consider health status in the model $[8,61,62]$. Some studies have recommended using a synergy index, which detects interactive effects that explain the impact of SEP factors on health outcomes [63]. As of yet, only one study [44] in this review calculated the interaction values of various SEP indicators.

Second, the majority of the studies measured SEP cross-sectionally, rather than over time. SEP is not static, and it may be more or less applicable at different time points in different contexts [11]. For example, occupational measures cannot be readily applied to people who are not currently employed [2].
Traditional measures of income at one point in time may fail to capture information about income fluctuation [2]; as an alternative, lifetime earning capacity has been suggested. However, a consensus has not yet been reached on building processes or improving calculations of these measures in the cardiovascular research field. Thus, studies need to validate the reliability and feasibility of commonly used measures to capture the dynamic and actual impact of SEP on CVH.

Third, studies were constrained by objective SEP measures. SEP encompasses subjective perceptions of social class and social status, and has been identified as a robust predictor of physical health in many societies [64]; therefore, subjective SEP is another option to consider. For example, Allen et al. [65] examined subjective SEP (i.e., the individual's perception of their own position in the social hierarchy), and found that subjective SEP was an independent predictor of 10-year CVD risk and lower subjective SEP was associated with higher CVD risk.

Beyond compositional measures, studies focused on aggregate SEP measures. Five studies analyzed in this review demonstrated that the socioeconomic causes of $\mathrm{CVH}$ disparities can encompass organizational-level SEP factors, such as one's working conditions. In Korea, there have been pervasive workrelated injustices based on hierarchies of occupations across industrial sectors [66]. In particular, vulnerable workers such as informal, contract, and manual workers have been repetitively exposed to occupational hazards in numerous social, physical, and psychological aspects $[66,67]$. However, the included studies utilized only physical aspects as measures of disparity among these groups, such as hazardous work environments.

Five studies adopted community-level SEP factors, such as significant area characteristics, and analyzed the data by county or borough boundaries. From a methodological standpoint, the validity of such area-based measures is dependent on whether the geographical units are meaningful [9]. Western research on disparities has underscored the efficacy of using of smaller geographical units to explain geographical disparities [68]. For example, the relevant area to provide insights into a population's health status may be the block group or census block in which a person resides $[68,69]$. However, comparable research in Korea is scarce, as none of the reviewed studies stratified the data into smaller administrative units such as neighborhoods, townships, or towns. Though analyses based on such routinely encountered settings have limited relevance to policy, they can have direct implications for improvements in the quality, equity, and efficiency of healthcare 
resource allocation [70].

Three studies included welfare status as a societal-level SEP parameter contributing to $\mathrm{CVH}$ disparities. Welfare status and its redistributive policies are among the "upstream" factors that most strongly affect health [2]. Particularly in Korea, the limited benefit coverage in the Medical Aid system considers all work as a barrier to healthcare utilization, widening the health gap between NHI recipients and Medical Aid recipients [71]. However, societal-level measures are not fully understood through the findings of this review; they can be broadly defined as including all upstream factors that generate, configure, and maintain social hierarchies of health such as social and public policies, laws, or systems of care [2]. Indeed, these factors were put forward as a guiding framework for action in eliminating $\mathrm{CVH}$ disparities [72]. In Korea, policies for CVD prevention [73], changes in laws regarding health insurance [74], and the cost of medical care [74] may further constitute broader-level factors that influence a population's CVH status in society.

Only four studies adopted multi-level models to illustrate the combined contribution of different levels of SEP to CVH. Increased attention is being paid to multilevel analyses due to the limitations of traditional SEP measures and the belief that the context in which one lives is as critical an influence as individual SEP factors [9]. These results highlight important theoretical arguments, which emphasize that interactions among several socioeconomic domains at the individual, organizational, community, and societal levels affect health outcomes in an individual's life $[75,76]$. Indeed, several lines of research have proposed that multiple socioeconomic levels may be synergistically predictive of CVH outcomes [77,78].

Three studies included in this review employed the area-deprivation index, and overwhelmingly used the Carstairs Index [79]. This contrasts with Western studies, in which researchers have developed and adopted a wide range of indices such as the Index of Multiple Deprivation [80], the Townsend Material Deprivation Score [81], and the Underprivileged Area Score [82]; these can be considered for future analyses in Korea. However, the area-deprivation index may be valid in one country but irrelevant in another, as it is influenced by country-specific geographical characteristics [83]. Thus, using an index that is originally developed and established for the Korean context is warranted, and researchers should further develop and test such an index to specifically predict CVH outcomes for area-wide planning.

Lastly, 4 studies measured early-life SEP or changes in SEP across the lifespan and examined how they became embodied to affect CVH outcomes in later life. The concept of these measures can be explained by the sensitive period model and social mobility model in the life-course approach [84]. However, the life-course model offers a more comprehensive measure of a particular SEP variable's effects over time [9]. For instance, the pathway hypothesis highlights the enduring and subsequent impact of SEP trajectories on health [84]. The accumulation hypothesis emphasizes the accumulated effects of social and economic (dis)advantages of SEP on health [84]. Meanwhile, cardiovascular studies that employed life-course SEP measures utilized several investigator-created SEP measures related to 4 life-course models and considered their effects simultaneously within the same analytic model $[85,86]$. However, these models are uncommon in statistical analyses in Korea, partly due to a lack of survey data infrastructure on time-variant factors in the secondary data, and because most studies are based on cross-sectional designs, which do not take changing circumstances across the life course into account.

\section{Limitations}

Our results may have been affected by several limitations. First, the disparity outcome was limited to $\mathrm{CVH}$ outcomes, so the scope of this review is limited. In particular, the diversity of the actual use of SEP in Korea in association with other contexts could be easily underestimated. For instance, an area-deprivation index appropriate to the Korean context has been developed in correlation with the total mortality rate (including mortality from (VD) and has been used to explore the relationship of deprivation with the total mortality rate $[83,87]$ so that the volume of research in this field may have been deemphasized.

Second, the methodological issues regarding SEP measures could not be analyzed in terms of structural stratifiers linked to SEP (e.g., gender and age), as none of the literature reviewed here employed differentiated SEP measures that stratified subgroups by such factors. Efforts to do so are warranted in future research, as many commonly used compositional and contextual SEP measures are limited in terms of their usefulness when examining the effect of SEP on outcomes in analyses of data that include gender and age subgroups. Particularly for women, household income may not be a useful indicator, especially in the context of gender divisions in labor and power within a household [2]. Problems may also exist in the use of the standard occupational classification system that is 
commonly validated among working men [2]. Furthermore, the meaning of "neighborhood" is heterogeneous and may not be the most relevant for all ages; for example, adults spend many of their waking hours at their workplace [6].

\section{CONCLUSION}

The current study reviewed the various SEP measures utilized in CVH disparity research in Korea and discussed the salient considerations of each measure. This paper concludes with the following implications. First, there is a need to systemically discuss ways to properly quantify compositional SEP measures of CVH disparities. Second, contextual SEP measures should be validated in the Korean context; this will require that studies focus on a comprehensive set of work-related factors associated with CVH status; the use of different units for exploring why place matters for $\mathrm{CVH}$, including neighborhoods, townships, and towns; and a wider range of upstream determinants that can affect CVH status on the societal level. Third, models should simultaneously consider different SEP levels. Fourth, more efforts are warranted to develop a number of reliable, novel composite indices to measure area characteristics specific to Korea's circumstances. Lastly, improved data infrastructure should be ensured to enable life-course SEP measures.

\section{CONFLICT OF INTEREST}

The authors have no conflicts of interest associated with the material presented in this paper.

\section{ACKNOWLEDGEMENTS}

None.

\section{AUTHOR CONTRIBUTIONS}

Conceptualization: LCY. Funding acquisition: None. Methodology: LCY, LYH. Writing-original draft: LCY. Writing-review \& editing: LCY, LYH.

\section{ORCID}

\author{
Chi-Young Lee https://orcid.org/0000-0001-6860-452X \\ Yong-Hawn Lee https://orcid.org/0000-0002-3982-5160
}

\section{REFERENCES}

1. Lynch J, Kaplan G, Socioeconomic position. In: Berkam LF, Kawachi I, editors. Social epidemiology. New York: Oxford University Press; 2000, p. 13-35.

2. World Health Organization. A conceptual framework for action on the social determinants of health; 2010 [cited 2019 Jul 5]. Available from: https://apps.who.int/iris/bitstream/handle/ 10665/44489/9789241500852_eng.pdf.

3. de Mestral C, Stringhini S. Socioeconomic status and cardiovascular disease: an update. Curr Cardiol Rep 2017;19(11):115.

4. Institute of Medicine Committee on the Review and Assessment of the NIH's Strategic Research Plan and Budget to Reduce and Ultimately Eliminate Health Disparities; Thomson GE, Mitchell F, Williams MB. Examining the health disparities research plan of the national institutes of health: unfinished business. Washington, DC: National Academies Press; 2006, p. 320.

5. Clark AM, DesMeules M, Luo W, Duncan AS, Wielgosz A. Socioeconomic status and cardiovascular disease: risks and implications for care. Nat Rev Cardiol 2009;6(11):712-722.

6. Glymour MM, Clark CR, Patton KK. Socioeconomic determinants of cardiovascular disease: recent findings and future directions. Curr Epidemiol Rep 2014;1(2):89-97.

7. Jeffries N, Zaslavsky AM, Diez Roux AV, Creswell JW, Palmer RC, Gregorich SE, et al. Methodological approaches to understanding causes of health disparities. Am J Public Health 2019;109 (S1):S28-S33.

8. Cirino PT, Chin CE, Sevcik RA, Wolf M, Lovett M, Morris RD. Measuring socioeconomic status: reliability and preliminary validity for different approaches. Assessment 2002;9(2):145-155.

9. Shavers VL. Measurement of socioeconomic status in health disparities research. J Natl Med Assoc 2007;99(9):1013-1023.

10. Krieger N, Williams DR, Moss NE. Measuring social class in US public health research: concepts, methodologies, and guidelines. Annu Rev Public Health 1997;18:341-378.

11. Galobardes B, Shaw M, Lawlor DA, Lynch JW, Davey Smith G. Indicators of socioeconomic position (part 1). J Epidemiol Community Health 2006;60(1):7-12.

12. Kim GR, Nam CM. Temporal trends in educational inequalities in non-communicable diseases in Korea, 2007-2015. PLoS One 2017;12(12):e0190143.

13. Jung-Choi K, Khang YH, Cho HJ. Changes in contribution of causes of death to socioeconomic mortality inequalities in Korean adults. J Prev Med Public Health 2011;44(6):249-259.

14. Khang YH, Lynch JW, Kaplan GA. Health inequalities in Korea: 
age- and sex-specific educational differences in the 10 leading causes of death. Int J Epidemiol 2004;33(2):299-308.

15. Kim MH, Kim MK, Choi BY, Shin YJ. Educational disparities in the metabolic syndrome in a rapidly changing society--the case of South Korea. Int J Epidemiol 2005;34(6):1266-1273.

16. Kim OY, Kwak SY, Kim B, Kim YS, Kim HY, Shin MJ. Selected food consumption mediates the association between education level and metabolic syndrome in Korean adults. Ann Nutr Metab 2017;70(2):122-131.

17. Kim MH, Jung-Choi K, Ko H, Song YM. Educational inequality in obesity-related mortality in Korea. J Korean Med Sci 2017; 32(3):386-392.

18. Baek TH, Lee HY, Lim NK, Park HY. Gender differences in the association between socioeconomic status and hypertension incidence: the Korean Genome and Epidemiology Study (KoGES). BMC Public Health 2015;15:852.

19. Song YM, Ferrer RL, Cho SI, Sung J, Ebrahim S, Davey Smith G. Socioeconomic status and cardiovascular disease among men: the Korean national health service prospective cohort study. Am J Public Health 2006;96(1):152-159.

20. Shin HY, Kang HT. Recent trends in blood pressure according to economic status: Korean National Health and Nutrition Examination Survey from 2005 to 2015. Asia Pac J Public Health 2018;30(3):266-275.

21. Park YJ, Shin NM, Yoon JW, Choi J, Lee SJ. Comparison of cardiovascular health status and health behaviors in Korean women based on household income. J Korean Acad Nurs 2010; 40(6):831-843 (Korean).

22. Choi KK, Kim SH, Yoo KD, Kim HJ, Park Jl, Hwang S, et al. Variation in the rate of well-controlled status of chronic disease by income level in Korea: 2010 to 2015. Medicine (Baltimore) 2018; 97(34):e12059.

23. Han M, Park S, Park JH, Hwang SS, Kim I. Do police officers and firefighters have a higher risk of disease than other public officers? A 13-year nationwide cohort study in South Korea. BMJ Open 2018;8(1):e019987.

24. Jung-Choi K, Khang YH, Cho HJ. Socioeconomic differentials in cause-specific mortality among 1.4 million South Korean public servants and their dependents. J Epidemiol Community Health 2011;65(7):632-638.

25. Seo SR, Kim SY, Lee SY, Yoon TH, Park HG, Lee SE, et al. The incidence of stroke by socioeconomic status, age, sex, and stroke subtype: a nationwide study in Korea. J Prev Med Public Health 2014;47(2):104-112.

26. Choi DK, Yim J, Hong DH, Kim JK, Park SH, Youn ST. Socioeco- nomic differentials in stroke and cardiovascular disease mortality in Korea. Korean J Health Educ Promot 2006;23(2):109119 (Korean).

27. Kim KH, Lee KH, Lee SM, Lee SY, Lee YS, Lim KR, et al. The proportional mortality ratios of specific-cause mortality by occupation and education among men aged 20-64 in Korea (19932004). J Prev Med Public Health 2007;40(1):7-15 (Korean).

28. Khang YH, Lynch JW, Jung-Choi K, Cho HJ. Explaining age-specific inequalities in mortality from all causes, cardiovascular disease and ischaemic heart disease among South Korean male public servants: relative and absolute perspectives. Heart 2008;94(1):75-82.

29. Kim NH, Kim TJ, Kim NH, Choi KM, Baik SH, Choi DS, et al. Relative and combined effects of socioeconomic status and diabetes on mortality: a nationwide cohort study. Medicine (Baltimore) 2016;95(30):e4403.

30. Koh DH, Kim HR, Han SS, Jee SH. The relationship between socioeconomic position and the predicted risk of ischemic heart disease with using health risk appraisal. J Prev Med Public Health 2006;39(4):359-364 (Korean).

31. Yoon YS, Oh SW, Park HS. Socioeconomic status in relation to obesity and abdominal obesity in Korean adults: a focus on sex differences. Obesity (Silver Spring) 2006;14(5):909-919.

32. Lee DS, Kim YJ, Han HR. Sex differences in the association between socio-economic status and type 2 diabetes: data from the 2005 Korean National Health and Nutritional Examination Survey (KNHANES). Public Health 2013;127(6):554-560.

33. Park KJ, Lim GU, Hwangbo Y, Jhang WG. The impact of health behaviors and social strata on the prevalence of cardio-cerebrovascular disease. Soonchunhyang Med Sci 2011;17(2):105111 (Korean).

34. Liao D, Cooper L, Cai J, Toole J, Bryan N, Burke G, et al. The prevalence and severity of white matter lesions, their relationship with age, ethnicity, gender, and cardiovascular disease risk factors: the ARIC Study. Neuroepidemiology 1997;16(3):149162.

35. Kim YJ, Lee JS, Park J, Choi DS, Kim DM, Lee KH, et al. Trends in socioeconomic inequalities in five major risk factors for cardiovascular disease in the Korean population: a cross-sectional study using data from the Korea National Health and Nutrition Examination Survey, 2001-2014. BMJ Open 2017;7(5): e014070.

36. Ki M, Lee YH, Kim YS, Shin JY, Lim J, Nazroo J. Socioeconomic inequalities in health in the context of multimorbidity: a Korean panel study. PLoS One 2017;12(3):e0173770. 
37. Cha SH, Park HS, Cho HJ. Socioeconomic disparities in prevalence, treatment, and control of hypertension in middle-aged Koreans. J Epidemiol 2012;22(5):425-432.

38. Kim JY, Kim SH, Cho YJ. Socioeconomic status in association with metabolic syndrome and coronary heart disease risk. Korean J Fam Med 2013;34(2):131-138.

39. Min H, Chang J, Balkrishnan R. Sociodemographic risk factors of diabetes and hypertension prevalence in Republic of Korea. Int J Hypertens 2010;2010:410794.

40. Lim H, Nguyen T, Choue R, Wang Y. Sociodemographic disparities in the composition of metabolic syndrome components among adults in South Korea. Diabetes Care 2012;35(10): 2028-2035.

41. Rosengren A, Teo K, Rangarajan S, Kabali C, Khumalo I, Kutty VR, et al. Psychosocial factors and obesity in 17 high-, middleand low-income countries: the Prospective Urban Rural Epidemiologic study. Int J Obes (Lond) 2015;39(8):1217-1223.

42. Park SJ, Kang HT, Nam CM, Park BJ, Linton JA, Lee YJ. Sex differences in the relationship between socioeconomic status and metabolic syndrome: the Korean National Health and Nutrition Examination Survey. Diabetes Res Clin Pract 2012; 96(3):400-406.

43. Khang $\mathrm{YH}$, Kim HR. Socioeconomic Inequality in mortality using 12-year follow-up data from nationally representative surveys in South Korea. Int J Equity Health 2016;15:51.

44. Chung W, Kim J, Lim SJ, Lee S. Sex-specific role of education on the associations of socioeconomic status indicators with obesity risk: a population-based study in South Korea. PLoS One 2018;13(1):e0190499.

45. Kang MY, Kim HR. Association between voluntary/involuntary job loss and the development of stroke or cardiovascular disease: a prospective study of middle-aged to older workers in a rapidly developing Asian country. PLoS One 2014;9(11): e113495.

46. Hwang WJ, Park Y. Ecological correlates of cardiovascular disease risk in Korean blue-collar workers: a multi-level study. J Korean Acad Nurs 2015;45(6):857-867 (Korean).

47. Kim BJ, Lee SH, Ryu WS, Kim CK, Chung JW, Kim D, et al. Excessive work and risk of haemorrhagic stroke: a nationwide casecontrol study. Int J Stroke 2013;8 Suppl A100:56-61.

48. Yoon CG, Kang MY, Bae KJ, Yoon JH. Do working hours and type of work affect obesity in south Korean female workers? Analysis of the Korean Community Health Survey. J Womens Health (Larchmt) 2016;25(2):173-180.

49. Jang TW, Kim HR, Lee HE, Myong JP, Koo JW. Long work hours and obesity in Korean adult workers. J Occup Health 2014; 55(5):359-366.

50. Cho KH, Lee SG, Nam CM, Lee EJ, Jang SY, Lee SH, et al. Disparities in socioeconomic status and neighborhood characteristics affect all-cause mortality in patients with newly diagnosed hypertension in Korea: a nationwide cohort study, 20022013. Int J Equity Health 2016;15:3.

51. Park SY, Kwak JM, Seo EW, Lee KS. Spatial analysis of the regional variation of hypertensive disease mortality and its socio-economic correlates in South Korea. Geospat Health 2016; 11(2):420.

52. Ahn KO, Shin SD, Hwang SS, Oh J, Kawachi I, Kim YT, et al. Association between deprivation status at community level and outcomes from out-of-hospital cardiac arrest: a nationwide observational study. Resuscitation 2011;82(3):270-276.

53. Hong JS, Kang HC. Regional differences in treatment frequency and case-fatality rates in Korean patients with acute myocardial infarction using the Korea national health insurance claims database: findings of a large retrospective cohort study. Medicine (Baltimore) 2014;93(28):e287.

54. Lee J, Bahk J, Kim I, Kim YY, Yun SC, Kang HY, et al. Geographic variation in morbidity and mortality of cerebrovascular diseases in Korea during 2011-2015. J Stroke Cerebrovasc Dis 2018;27(3):747-757.

55. Shin J, Cho KH, Choi Y, Lee SG, Park EC, Jang Sl. Combined effect of individual and neighborhood socioeconomic status on mortality in patients with newly diagnosed dyslipidemia: a nationwide Korean cohort study from 2002 to 2013. Nutr Metab Cardiovasc Dis 2016;26(3):207-215.

56. Kim Y, Oh J, Jha A. Contribution of hospital mortality variations to socioeconomic disparities in in-hospital mortality. BMJ Qual Saf 2014;23(9):741-748.

57. Song YM, Smith GD, Sung J. Adult height and cause-specific mortality: a large prospective study of South Korean men. Am J Epidemiol 2003;158(5):479-485.

58. Choi BY, Lee DC, Chun EH, Lee JY. The relationship between metabolic syndrome and childhood maternal education level, job status findings from the Korean National Health and Nutrition Examination, 2007-2009. Korean J Fam Med 2014; 35(4):207-215.

59. Ko MJ, Kim MK. The relationship between high blood glucose and socio-economic position in childhood and adulthood in Korea: findings from the Korean National Health and Nutrition Examination, 2007-09. Int J Epidemiol 2012;41(3):733-742.

60. Braveman PA, Cubbin C, Egerter S, Chideya S, Marchi KS, Met- 
zler M, et al. Socioeconomic status in health research: one size does not fit all. JAMA 2005;294(22):2879-2888.

61. Cabieses B, Tunstall H, Pickett K. Understanding the socioeconomic status of international immigrants in Chile through hierarchical cluster analysis: a population-based study. Int Migr 2015;53(2):303-320.

62. da Veiga Pessoa DM, Roncalli AG, de Lima KC. Economic and sociodemographic inequalities in complete denture need among older Brazilian adults: a cross-sectional populationbased study. BMC Oral Health 2016;17(1):5.

63. Ahnquist J, Wamala SP, Lindstrom M. Social determinants of health--a question of social or economic capital? Interaction effects of socioeconomic factors on health outcomes. Soc Sci Med 2012;74(6):930-939.

64. Nobles J, Weintraub MR, Adler NE. Subjective socioeconomic status and health: relationships reconsidered. Soc Sci Med 2013;82:58-66.

65. Allen AJ, McNeely JM, Waldstein SR, Evans MK, Zonderman $A B$. Subjective socioeconomic status predicts Framingham cardiovascular disease risk for whites, not blacks. Ethn Dis 2014;24(2):150-154.

66. Min JY, Park SG, Kim SS, Min KB. Workplace injustice and selfreported disease and absenteeism in South Korea. Am J Ind Med 2014;57(1):87-96.

67. Landsbergis PA, Grzywacz JG, LaMontagne AD. Work organization, job insecurity, and occupational health disparities. Am J Ind Med 2014;57(5):495-515.

68. Vaughan AS, Quick H, Pathak EB, Kramer MR, Casper M. Disparities in temporal and geographic patterns of declining heart disease mortality by race and sex in the United States, 1973-2010. J Am Heart Assoc 2015;4(12):e002567.

69. Mensah GA, Goff DC, Gibbons GH. Cardiovascular mortality differences-place matters. JAMA 2017;317(19):1955-1957.

70. Osypuk TL, Galea S. What level macro? Choosing appropriate levels to assess how place influences population health. In: Galea S, editor. Macrosocial determinants of population health. New York: Springer; 2017, p. 399-435.

71. Hwang J. Understanding reasons for unmet health care needs in Korea: what are health policy implications? BMC Health Serv Res 2018;18(1):557.

72. Mensah GA. Eliminating disparities in cardiovascular health: six strategic imperatives and a framework for action. Circulation 2005;111(10):1332-1336.

73. Cho HW, Chu C. Evaluation of self-assessment in cardiovascular diseases among Korean older population. Osong Public
Health Res Perspect 2016;7(2):75-76.

74. Lee HY. Socioeconomic disparities in the prevalence, diagnosis, and control of hypertension in the context of a universal health insurance system. J Korean Med Sci 2017;32(4):561-567.

75. National Institute on Minority Health and Health Disparities. National institute on minority health and health disparities research framework; 2018 [cited 2019 Jan 1]. Available from: https://www.nimhd.nih.gov/images/research-frameworkslide.pdf.

76. Reifsnider E, Gallagher M, Forgione B. Using ecological models in research on health disparities. J Prof Nurs 2005;21(4): 216-222.

77. Brown AF, Liang LJ, Vassar SD, Stein-Merkin S, Longstreth WT $\mathrm{Jr}$, Ovbiagele B, et al. Neighborhood disadvantage and ischemic stroke: the Cardiovascular Health Study (CHS). Stroke 2011;42(12):3363-3368.

78. Okwuosa IS, Lewsey SC, Adesiyun T, Blumenthal RS, Yancy CW. Worldwide disparities in cardiovascular disease: challenges and solutions. Int J Cardiol 2016;202:433-440.

79. Carstairs V, Morris R. Deprivation: explaining differences in mortality between Scotland and England and Wales. BMJ 1989; 299(6704):886-889.

80. Jordan H, Roderick P, Martin D. The Index of Multiple Deprivation 2000 and accessibility effects on health. J Epidemiol Community Health 2004;58(3):250-257.

81. Townsend P, Philimore P, Beattle A. Health and deprivation: inequalities and the north. London: Routledge; 1989, p. 165.

82. Jarman B. Underprivileged areas: validation and distribution of scores. Br Med J (Clin Res Ed) 1984;289(6458):1587-1592.

83. Shin H, Lee S, Chu JM. Development of composite deprivation index for Korea: the correlation with standardized mortality ratio. J Prev Med Public Health 2009;42(6):392-402 (Korean).

84. Kuh D, Ben-Shlomo Y. A life course approach to chronic disease epidemiology. Oxford: Oxford University Press; 2004, p. 494.

85. Chichlowska KL, Rose KM, Diez-Roux AV, Golden SH, McNeill AM, Heiss G. Life course socioeconomic conditions and metabolic syndrome in adults: the Atherosclerosis Risk in Communities (ARIC) Study. Ann Epidemiol 2009;19(12):875-883.

86. Walsemann KM, Goosby BJ, Farr D. Life course SES and cardiovascular risk: heterogeneity across race/ethnicity and gender. Soc Sci Med 2016;152:147-155.

87. Choi MH, Cheong KS, Cho BM, Hwang IK, Kim CH, Kim MH, et al. Deprivation and mortality at the town level in Busan, Korea: an ecological study. J Prev Med Public Health 2011;44(6):242248. 